\title{
Trends in burden and risk factors associated with childhood stunting in Rwanda from 2000 to 2015: policy and program implications
}

Agnes Binagwaho ${ }^{1,2,3^{*+}}$ D , Alphonse Rukundo ${ }^{4+}$, Samuel Powers ${ }^{1,5}$, Kateri B. Donahoe ${ }^{1}$, Mawuena Agbonyitor ${ }^{6}$, Fidel Ngabo ${ }^{7}$, Corine Karema ${ }^{1}$, Kirstin Woody Scott ${ }^{2}$ and Mary C. Smith Fawzi ${ }^{2}$

\begin{abstract}
Background: Rwanda has made substantial economic progress over the past two decades. However, evidence suggests that malnutrition among children remains high in spite of this progress. This study aims to examine trends and potential risk factors associated with childhood stunting from 2000 to 2015 in Rwanda.

Methods: Data for this study come from the 2000 to 2015 Rwanda's Demographic and Health Surveys (DHS), a cross-sectional, population-based survey that is conducted every 5 years. Following prior work, we define stunting based on age and weight as reported in the DHS. We assess the overall prevalence of stunting among children under the age of 5 in Rwanda and then conduct bivariate analyses across a range of policy-relevant demographic, socioeconomic, and health variables. We then incorporate key variables in a multivariable analysis to identify those factors that are independently associated with stunting.

Results: The prevalence of stunting among children under the age of 5 in Rwanda declined from 2000 (47.4\%) to 2015 (38.3\%), though rates were relatively stagnant between 2000 and 2010. Factors associated with higher rates of stunting included living in the lowest wealth quintile, having a mother with limited education, having a mother that smoked, being of the male sex, and being of low-birth weight.

Conclusions: Though overall stunting rates have improved nationally, these gains have been uneven. Furthering ongoing national policies to address these disparities while also working to reduce the overall risk of malnutrition will be necessary for Rwanda to reach its overall economic and health equity goals.
\end{abstract}

Keywords: Malnutrition, Rwanda, Children, Stunting, Global health

\section{Background}

Malnutrition is a leading cause of mortality among children around the world, with over 6 million deaths occurring each year $[1,2]$. In addition to accounting for more than one-third of child mortality worldwide, the morbidity stemming from malnutrition is of serious consequence as it negatively impacts a child's future growth and development. Malnutrition is associated with stunting as well as

\footnotetext{
* Correspondence: agnes_binagwaho@hms.harvard.edu

${ }^{\dagger}$ Agnes Binagwaho and Alphonse Rukundo are co-first authors.

${ }^{1}$ University of Global Health Equity, Kigali Heights, Plot 772, KG 7 Ave., 5th Floor, PO Box 6955, Kigali, Rwanda

${ }^{2}$ Harvard Medical School, Boston, MA, USA

Full list of author information is available at the end of the article
}

impaired cognitive development, which can result in poor educational outcomes [3, 4]. Longer term, this educational deficit negatively impacts children's economic security as they transition into adulthood, as well as overall national productivity $[5,6]$.

Fortunately, chronic malnutrition among children as measured by the resultant effect of stunting has declined globally by an estimated 40 million cases between 1980 and 2000 [7]. However, this progress has not been evenly distributed throughout the world [7]. For instance, some studies have shown an overall modest decline in stunting across Africa, with the overall prevalence decreasing from $40.5 \%$ in 1980 to $35.2 \%$ in 2000; yet other evidence over

(c) The Author(s). 2020 Open Access This article is distributed under the terms of the Creative Commons Attribution 4.0 International License (http://creativecommons.org/licenses/by/4.0/), which permits unrestricted use, distribution, and reproduction in any medium, provided you give appropriate credit to the original author(s) and the source, provide a link to the Creative Commons license, and indicate if changes were made. The Creative Commons Public Domain Dedication waiver (http://creativecommons.org/publicdomain/zero/1.0/) applies to the data made available in this article, unless otherwise stated. 
this same period demonstrates a rise in stunting within a subset of African countries, including Rwanda, rural Ethiopia, and Côte d'Ivoire, among other countries [7]. The region of East Africa, where Rwanda is situated, witnessed not only the highest rates of stunting but also was the only region to witness a net increase in the prevalence of stunting from 1980 to 2000 (by $0.08 \%$ per year) [7].

In Rwanda, the burden of malnutrition may have increased due to the severe political and economic crisis surrounding the 1994 genocide [8]. Since this time, Rwanda has taken a number of progressive steps towards recovery and economic growth as outlined in its Vision 2020 plan which was issued in 2002 [9]. Correspondingly, the health of the population has improved dramatically across an array of population health parameters [10]. For instance, between 2000 and 2015, modern contraceptive use has increased from 3.4 to $27.8 \%$ among women of reproductive age, vaccination rates have improved markedly, there has been a $70.1 \%$ decline in infant mortality, and a reduction in under-5 mortality from 196 deaths per 1000 live births to 50 deaths per 1000 live births [11]. This progress is related to comprehensive reforms and innovations designed with community engagement to strengthen the health system, including but not limited to some of the following policies: implementing the community-based health insurance plan (known as Mutuelles de Santé) to improve financial access to care; developing a robust community health worker network to provide care at the village level; and, creating performance-based financing programs to increase the quality of health care services [12-14].

Despite this national progress in health outcomes, malnutrition remains a serious burden among Rwandan children under the age of five, with the rate of stunting remaining relatively stagnant [15-17]. Given that the persistent burden of stunting conflicts with the overall improvements in health outcomes in the country, this study aims to examine trends and explore potential risk factors associated with childhood stunting from 2000 to 2015 in Rwanda. A greater understanding of the policy-relevant factors associated with enduring childhood stunting will help to inform the development of more effective programs and policies to address this persistent challenge.

\section{Methods}

\section{Study design}

Data for this study come from Rwanda's Demographic and Health Survey (DHS) between 2000 and 2015 [15, 16, $18,19]$. The DHS is a cross-sectional survey conducted every 5 years by the Rwandan National Institute of Statistics in collaboration with the Ministry of Health. Additional financial and technical support is provided from Macro Measure DHS, non-governmental organizations, and bilateral and multilateral organizations [15, 16, 18, 19].

\section{Sample}

The DHS comprises a nationally representative sample of $9696,10,272,12,540$, and 12,699 households with a response rate of 99.5, 99.7, 99.8, and 99.9\% from 2000, 2005 , 2010, and 2015, respectively. Data on anthropometric measurements were collected in $50 \%$ of households selected for survey. All women aged 15-49 and children under age 5 were measured. Data on nutritional status were analyzed for $6287,3765,4076$, and 3538 children respectively, in 2000, 2005, 2010, and 2015 [15, 16, $18,19]$.

\section{Variables}

The DHS collects data on a variety of demographic, socioeconomic, and health variables, including maternal and child health, anthropometric measurements, male circumcision rates, domestic violence, expenditures on health care, and ownership and use of anti-malarial bed nets. This study relied upon the standard DHS questions related to feeding practices of infants and young children administrated by trained DHS interviewers as well as anthropometric data systematically measured from the subsampled group (e.g., the height, age, and sex of the child) $[15,16,18,19]$.

Child nutritional status was assessed using the 2006 World Health Organisation (WHO) child growth standards across the time series of interest in this study. Following prior work, we classify children as stunted for their age if their height-for-age Z-scores fall below two standard deviations $(-2 \mathrm{SD})$ away the mean of the reference population; these children would be in the bottom $2.5 \%$ percentile for height for their age group [20, 21]. The height measurements were carried out using a Shorr measuring board for infants produced under the guidance of the United Nations International Children's Emergency Fund (UNICEF). Children younger than 24 months were measured lying down (recumbent length) on the board, whereas older children were measured using standard height $[15,19,22]$. For this analysis, we recalculated the prevalence of stunting in accordance to the $2006 \mathrm{WHO}$ guidelines in order to ensure comparability over time as changes in the definition occurred throughout the time series [16, 18].

In terms of covariates, we captured a number of policyrelevant maternal and individual characteristics that are known to influence stunting. Maternal factors included the following: age, education level, employment, history of smoking, and marital status. Other variables of interest included the child's birth weight, wealth quintile (which served as a proxy for socioeconomic status), household setting (rural versus urban), and the number of children under 5 years of age in the household. Education level had three categories: no formal education, only primary education, and secondary/post-secondary education. A child's birth weight was categorized based on medical records 
and/or maternal recall. Children with a weight less than $2.5 \mathrm{~kg}$ were classified as low birth weight. The wealth index variable is compiled by the DHS using information regarding ownership of durable goods (e.g., a television, radio, car, etc.) and housing characteristics (e.g., source of drinking water, type of flooring material, access to electricity, etc.) and adjusts for area-specific (urban versus rural) factors scores to create a nationally-applicable combined wealth index. National wealth quintiles are created by ranking each household member based on his or her assigned index scores and then dividing the population based on these scores into quintiles each comprised of $20 \%$ of the population $[15,16,18,19,23]$. Though maternal height is a variable captured by the DHS and some prior work has shown it to be associated with stunting [24], other studies have shown mid-parental height as a more useful metric [25]. Further, a measure of parental height was not included in this analysis given both the lack of it being amenable to actional policy measures and it being of a particularly sensitive nature within the Rwandan context.

\section{Analysis}

We provide descriptive statistics for the study sample characteristics. Summary descriptive measures, including proportions with 95\% confidence intervals for categorical variables, were estimated. Childhood stunting was assessed by height-for-age Z-scores, based on 2006 WHO Child Growth Standards. We then performed bivariate analyses using Pearson chi-squared tests to examine the association between stunting in children and a number of independent predictor variables including household, maternal, and child variables. The choice of the independent variables was based on variables collected and available in the DHS data sets and on the literature reviews on the socio-demographic characteristics influencing childhood stunting. Finally, we used logistic regression to identify variables associated with childhood stunting. For these multivariable analyses, we included all variables that were statistically significant at $10 \%$ in bivariate analysis into the model. We used the HosmerLemeshow goodness-of-fit test to assess the performance of our logistic regression model. For all analyses, $p$-values less than 0.05 were considered to be statistically significant. We present the resulting odds ratios with their corresponding 95\% confidence intervals. Statistical analyses were performed using Stata (version 12) [26] and R (version 3.3.2) [27].

\section{Results}

Trend in the prevalence of childhood stunting from 2000 to 2015

The prevalence of stunting among children under five in Rwanda was relatively stagnant between 2000 and 2010 but showed an overall decline nationally from $47.4 \%$ in 2000 to $38.3 \%$ in 2015 ( $p$-value $<0.001$ ) (Table 1$)$.
Bivariate analysis: prevalence of childhood stunting by household, maternal, and child characteristics

The risk of stunting was associated with lower household economic status for all time periods. The prevalence of childhood stunting was persistently higher among families from the poorest wealth quintile, remaining relatively stable between 2000 and 2015, (51.4\% vs. $48.3 \%$, respectively); whereas, children in households in the highest wealth quintile demonstrated an overall decline during that same time period ( $29.3 \%$ vs. $21.6 \%)$. While stunting among children under five in the highest wealth index households increased from $29.3 \%$ in 2000 to $36.6 \%$ in 2005, it fell to $21.8 \%$ by 2015 (Fig. 1). Moreover, childhood stunting was more prevalent among those living in rural areas relative to urban areas ( $40.8 \%$ versus $25.9 \%$ in 2015 , respectively).

Regarding maternal factors, the childhood stunting rate was significantly higher among families with poorly educated mothers across all years relative to households with a mother who had higher levels of education ( $p$-value $<$ 0.001) (Table 1). Childhood stunting was also significantly greater among households where the mother smokes relative to households with non-smoking mothers (p-value $<$ 0.001 ), ranging from $55.2 \%$ in 2000 to $58.2 \%$ in 2015 for smoking households to $46.9 \%$ in 2000 to $39.6 \%$ in 2015 in non-smoking households.

With respect to individual characteristics, stunting was highest among children with a low birth weight (ranging from $50.0 \%$ in 2000 to $55.7 \%$ in 2015 and peaking at $63.3 \%$ in 2005) relative to those with normal-to-high birth weights (p-value $<0.01$ ). For age, the prevalence of stunting was greatest among children aged 24-35 months (58.9\% in $2000,61.9 \%$ in $2005,51.3 \%$ in 2010 , and $45.1 \%$ in 2015 ) relative to younger children ( $\mathrm{p}$-value $<0.01$ ). Further, stunting was greater among boys relative to girls ( $\mathrm{p}$ value $<.0001$ across all years) (Table 1 ).

\section{Multivariable analysis results: factors associated with childhood stunting}

In Table 2, we present the results of our multivariable analysis to examine factors associated with childhood stunting. The models included the following variables: sex, child age, birth weight, maternal education, mother's smoking history, place of residence, and wealth quintile.

\section{Household factors}

Lower economic status was associated with childhood stunting, with children under 5 years of age in the poorest households (lowest wealth index) having significantly higher odds of stunting relative to those in the richest (highest wealth index) households (Table 2). Over time, this disparity between rich and poor appeared to increase; in 2000 and 2005 there was no significant difference in stunting rates among children below the age of 5 


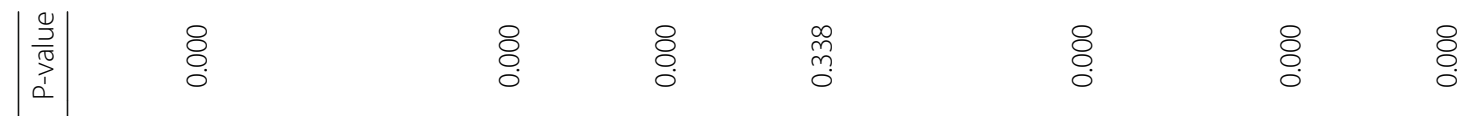

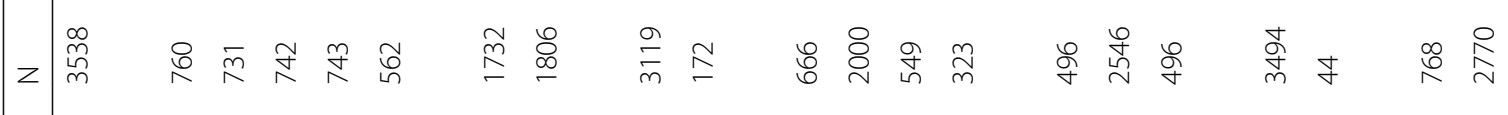

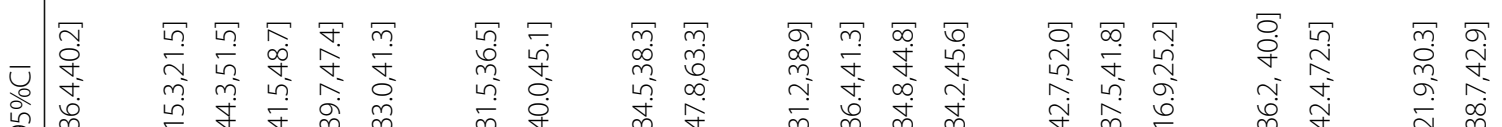

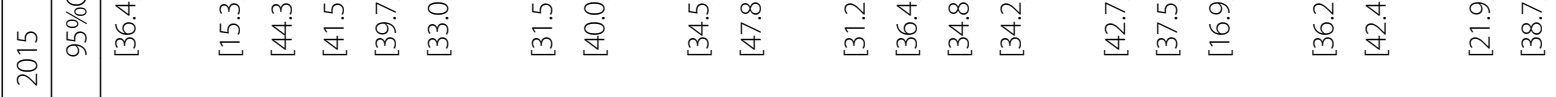
离

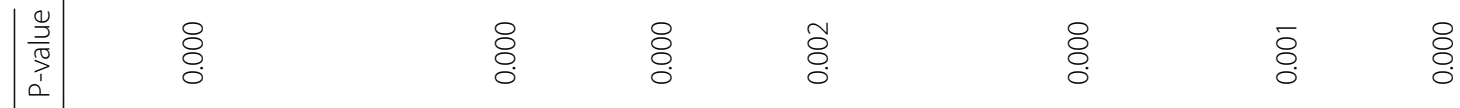

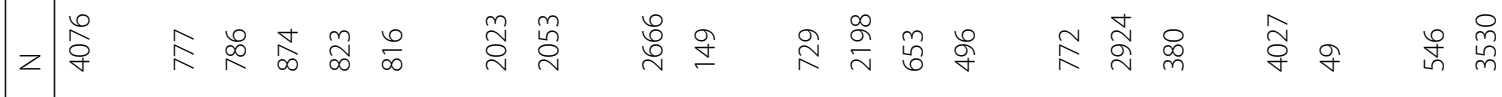

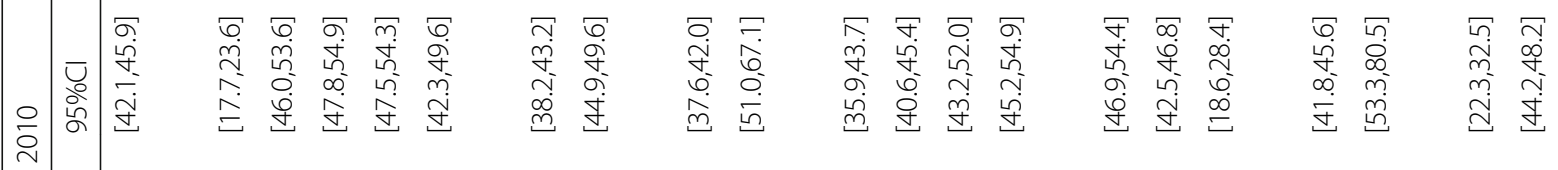

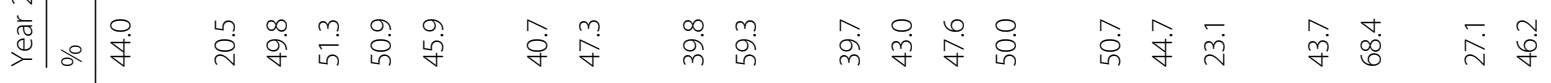

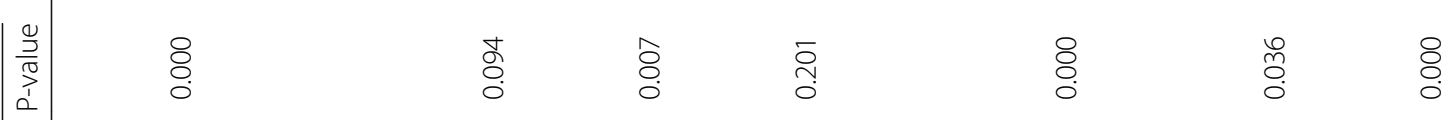

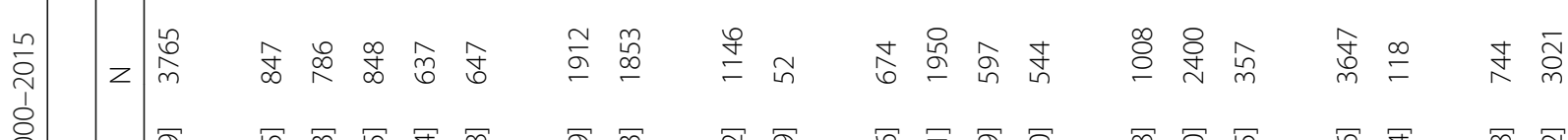

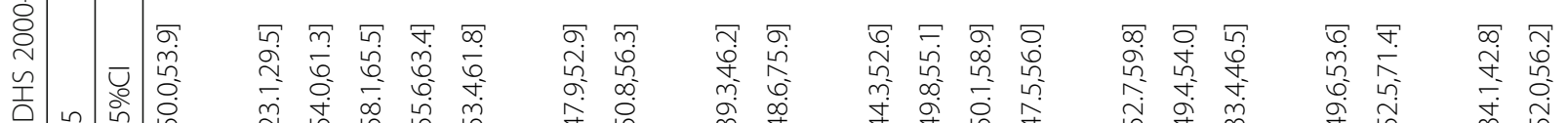

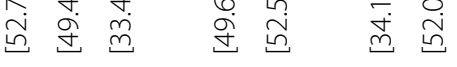

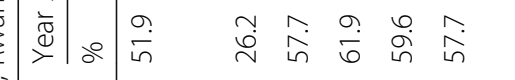

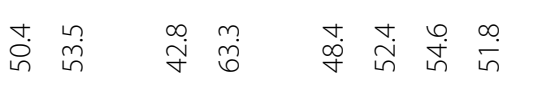

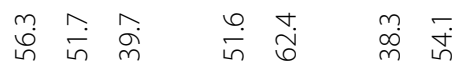
8 ஓ. ঃ. 용

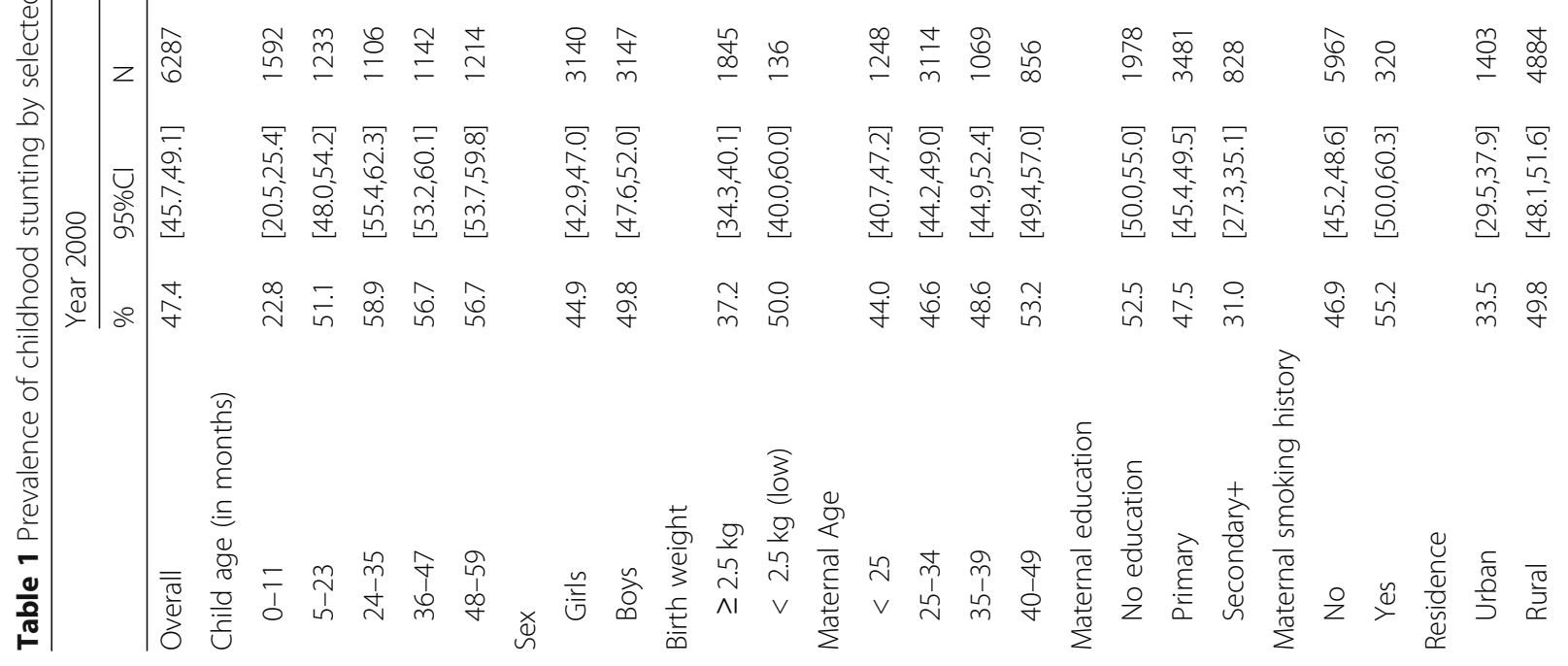




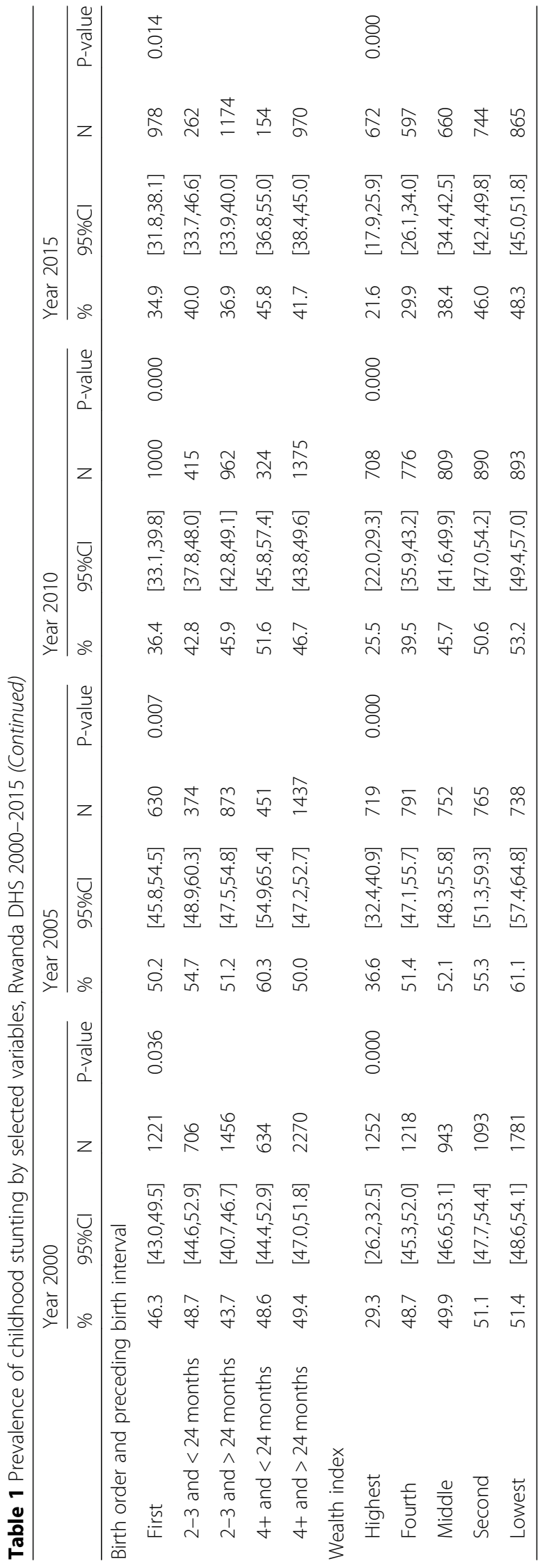

in the poorest households relative to the richest. However, children from the poorest households had 2.68 and 2.71 higher odds of stunting than children in the richest households in 2010 and 2015, respectively ( $p$-value< 0.001).

\section{Maternal factors}

There is a consistent inverse relationship between maternal education level and childhood stunting: the more schooling a mother has, the less likely her child is to be stunted. Specifically, in 2000, children below the age of 5 whose mothers attended primary school had lower odds of stunting than children whose mother had no education (odds ratio $(\mathrm{OR})=0.61, p$-value $<0.01$ ); and children whose mothers had a secondary and higher level of education had lower odds of stunting than those with mothers who had no education $(\mathrm{OR}=0.35$, $\mathrm{p}$-value $<$ $0.001)$. While this disparity was not statistically significant in 2005, it was significant in 2010 and 2015.

\section{Child factors}

Children classified as having a low birth weight (less than $2.5 \mathrm{~kg}$ ) had more than twice the odds of being stunted relative to those born with normal weight $(\mathrm{OR}=$ 2.57 in 2000 and $\mathrm{OR}=1.77$ in 2015). Similar to our bivariate results, the odds of stunting were greater after the first year of life: in 2015, children greater than 12 months of age tended to be an estimated 2.35 to 3.53 times more likely to experience stunting compared to children aged 12 months and below ( $p$-values $<0.001$ ) This represented a decrease from 2000 whereas older children were between 5.35 and 6.8 times as likely to experience stunting ( $p$-values $<0.001)$. Additionally, the analysis showed that boys were generally more likely to be stunted than girls (Table 2).

\section{Discussion}

This study identified a series of risk factors associated with childhood stunting in Rwanda. This analysis provides important evidence that malnutrition has persisted in spite of other improvements in the country's economy and health indicators and provides policymakers with guidance regarding particular at-risk populations for this persistent scourge on childhood well-being. Specifically, we found that living in a rural area, lower maternal education level, being in the lowest household wealth quintile, maternal smoking, being male, having a low birth weight, and being older than 1 year of age are risk factors associated with childhood stunting in Rwanda.

Our findings build upon prior work examining stunting in Rwanda and provide a more comprehensive time trend analysis. One cross-sectional study leveraging the 2015 DHS to identify risk factors for stunting similarly found that male sex, increased child age, low household wealth 


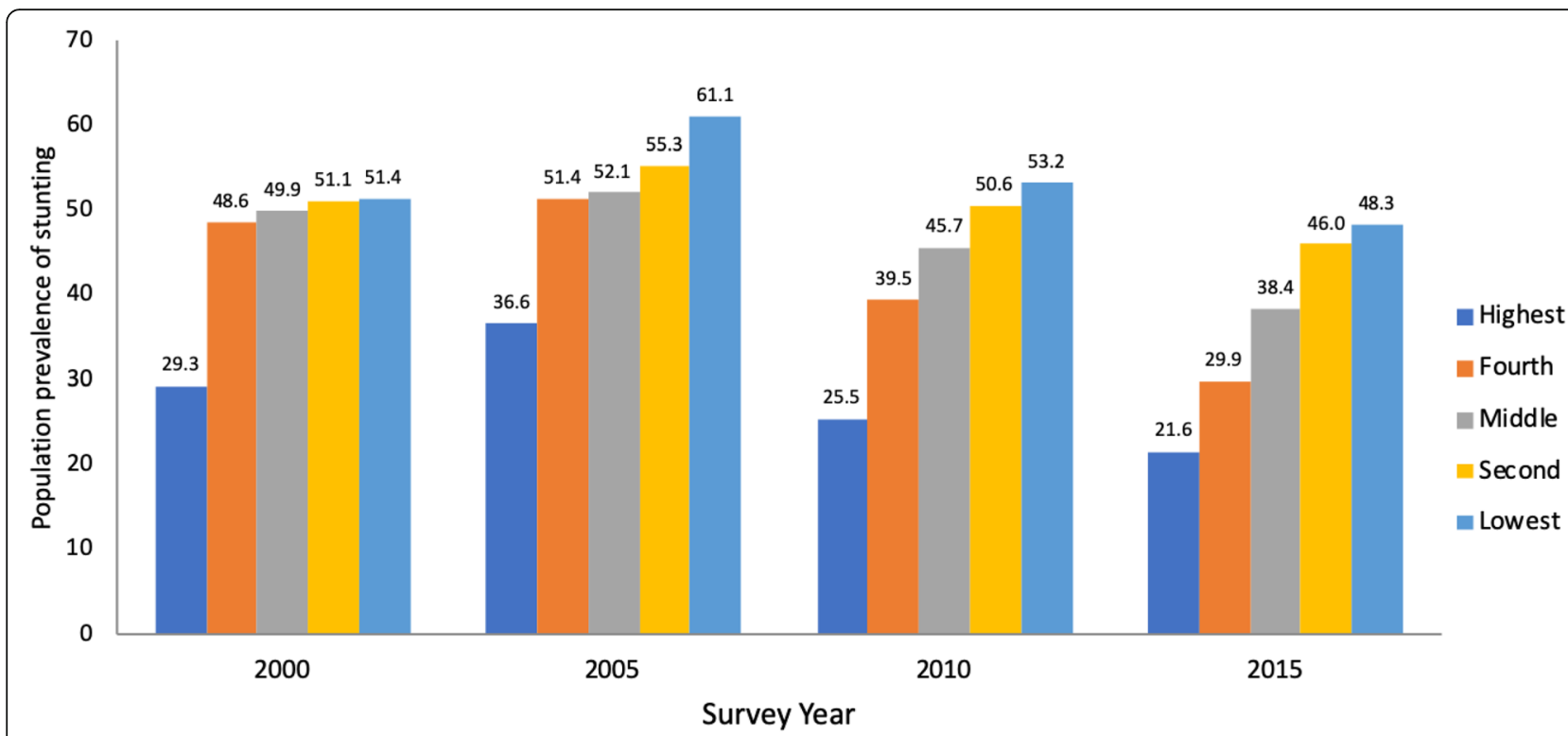

Fig. 1 Trends in Prevalence of Childhood Stunting in Rwanda, by Wealth Quintile. Notes: Rwanda's Demographic Health Survey (DHS) 2010 and DHS 2015 rely on the 2006 WHO standards whereas DHS 2000 \& 2005 do not. For consistency, all of our calculations were conducted according to the 2006 standards. As such, our calculations use a different definition of malnutrition in 2000 and 2005 than the DHS publications do for those years.

index, low birth weight, and lower maternal education level were risk factors for stunting [28]. They also found that low maternal height and a history of not taking deworming medicine during pregnancy were risk factors for stunting, suggesting areas for further analysis of these trends over time [28]. A study focused on the northern province of Rwanda found that increased child age was a risk factor for stunting and that both exclusive breastfeeding as well as use of deworming tablets in the previous 6 months were protective factors [29]. Further, Kirk et al. (2017) found a striking 78.3\% stunting prevalence rate among preterm/low birthweight children discharged from a hospital neonatal unit in rural Rwanda, which is nearly double the national stunting prevalence rate [30].

The associated risk factors for stunting among Rwandan children are comparable to those observed in other countries. In South Africa, one study found significantly higher levels of stunting among children under five from the poorest segment of society as compared to the richest; rural populations also demonstrated higher levels of stunting compared to their urban counterparts [31]. Additionally, a study on Indonesia found that severe stunting in children under the age of five was associated with low parental education, low household wealth index, child's age, and male sex [32]. Furthermore, in Uganda, a study identified similar risk factors for stunting, including low family socioeconomic status and limited maternal education [33]. A study in Mexico corroborates this finding, demonstrating that a lower level of maternal education is associated with the risk of stunted children [34].
A 141-country review of population-based data from 1985 to 2011 showed that economic gains were systematically associated with lower stunting prevalence [35]. However, our study shows that a high stunting prevalence has persisted in Rwanda, despite a growing economy. One contributing factor might be that families from the lowest wealth quintile tend to have the highest proportion of families with more than 5 members $(10.9 \%$ in 2000 to $18.7 \%$ in 2005) [16, 18]. This pattern, combined with the fact that the lowest quintile also experienced a stagnated prevalence in childhood stunting between 2000 and 2015, may help explain why a high prevalence of stunting is observed despite overall economic gains in the country, including a reduction in the proportion of the population living in poverty (from $58.9 \%$ in 2000 to $38.2 \%$ in 2015) [36]. In other words, as the poorest families - whose children are at the highest risk of stunting relative to others grow in size, the rate of childhood stunting has remained stagnant. A growing disparity in stunting between the rich and poor demonstrates that the significant progress made within the highest wealth quintile has not reached the poorest members of society, which necessitates closer attention given Rwanda's commitment to equity. Additionally, our findings suggest the importance of further broadening women's access to higher education, increasing access to reproductive and postnatal care to reduce the burden of low birthweight, improving uptake of family planning services, ensuring access to clean drinking water and sanitation, and promoting the cessation/prevention of maternal smoking are necessary to adequately tackle 
Table 2 Odds ratios (ORs) and 95\% confidence intervals (95\%Cls) for factors associated with childhood stunting, Rwanda DHS 20002015

\begin{tabular}{|c|c|c|c|c|c|c|c|c|}
\hline \multirow[t]{2}{*}{ Parameters } & \multicolumn{2}{|c|}{ Year 2000} & \multicolumn{2}{|c|}{ Year 2005} & \multicolumn{2}{|c|}{ Year 2010} & \multicolumn{2}{|c|}{ Year 2015} \\
\hline & $\mathrm{OR}$ & $95 \% \mathrm{Cl}$ & $\mathrm{OR}$ & $95 \% \mathrm{Cl}$ & $\mathrm{OR}$ & $95 \% \mathrm{Cl}$ & $\overline{O R}$ & $95 \% \mathrm{Cl}$ \\
\hline \multicolumn{9}{|l|}{ Sex } \\
\hline Girl & Ref & & Ref & & Ref & & Ref & \\
\hline Boy & $1.35^{*}$ & $(1.01-1.86)$ & 1.03 & $(0.77-1.38)$ & $1.53^{* * *}$ & $(1.25-1.86)$ & $1.51^{* * *}$ & $(1.30-1.76)$ \\
\hline \multicolumn{9}{|l|}{ Child age } \\
\hline $6-11$ & Ref & & Ref & & Ref & & Ref & \\
\hline $12-23$ & $5.34^{* * *}$ & $(3.46-8.24)$ & $4.16^{* * *}$ & $(2.60-6.66)$ & $4.48^{* * *}$ & $(3.21-6.25)$ & $3.48^{* * *}$ & $(2.56-4.71)$ \\
\hline $24-35$ & $6.42^{* * *}$ & $(3.92-10.5)$ & $3.65^{* * *}$ & $(2.29-5.82)$ & $4.73^{* * *}$ & $(3.43-6.53)$ & $3.53^{* * *}$ & $(2.63-4.76)$ \\
\hline $36-47$ & $5.86^{* * *}$ & $(3.29-10.4)$ & $3.84^{* * *}$ & $(2.33-6.33)$ & $5.68^{* * *}$ & $(4.02-8.01)$ & $3.15^{* * *}$ & $(2.27-4.37)$ \\
\hline $48-59$ & $6.80^{* * *}$ & $(3.58-12.9)$ & $2.75^{* * *}$ & $(1.65-4.61)$ & $3.77^{* * *}$ & $(2.63-5.39)$ & $2.35^{* * *}$ & $(1.71-3.23)$ \\
\hline \multicolumn{9}{|l|}{ Birth weight } \\
\hline$\geq 2.5 \mathrm{~kg}$ & Ref & & Ref & & Ref & & Ref & \\
\hline$<2.5 \mathrm{~kg}$ (low) & $2.57^{* * *}$ & $(1.31-5.05)$ & 1.59 & $(0.74-3.40)$ & $2.29^{* * *}$ & $(1.42-3.70)$ & $1.77^{* * *}$ & $(1.23-2.56)$ \\
\hline \multicolumn{9}{|l|}{ Maternal education } \\
\hline No education & Ref & & Ref & & Ref & & Ref & \\
\hline Primary & $0.61^{* *}$ & $(0.40-0.94)$ & 1.00 & $(0.68-1.47)$ & 0.89 & $(0.68-1.14)$ & 0.84 & $(0.68-1.05)$ \\
\hline Secondary or Higher & $0.35^{* * *}$ & $(0.20-0.60)$ & 0.78 & $(0.47-1.31)$ & $0.42^{* *}$ & $(0.26-0.66)$ & $0.48^{* * *}$ & $(0.34-0.69)$ \\
\hline \multicolumn{9}{|l|}{ Maternal smoking history } \\
\hline No & Ref & & Ref & & Ref & & Ref & \\
\hline Yes & 0.93 & $(0.41-2.14)$ & $4.93^{* *}$ & $(1.33-18.3)$ & $4.98^{* *}$ & $(1.59-15.60)$ & 1.67 & $(1.00-2.79)$ \\
\hline \multicolumn{9}{|l|}{ Place of residence } \\
\hline Urban & Ref & & Ref & & Ref & & Ref & \\
\hline Rural & 1.53 & $(0.980-2.39)$ & $1.44^{*}$ & $(1.01-2.06)$ & 1.34 & $(0.94-1.91)$ & 1.17 & $(0.86-1.60)$ \\
\hline \multicolumn{9}{|l|}{ Wealth quintile } \\
\hline Highest & Ref & & Ref & & Ref & & & \\
\hline Fourth & 0.86 & $(0.52-1.42)$ & $1.93^{* *}$ & $(1.25-2.99)$ & $1.56^{* *}$ & $(1.10-2.22)$ & 1.23 & $(0.85-1.77)$ \\
\hline Middle & 1.27 & $(0.65-2.46)$ & $1.74^{*}$ & $(1.07-2.82)$ & $1.61^{* *}$ & $(1.12-2.32)$ & $1.74^{* * *}$ & $(1.22-2.49)$ \\
\hline Second & 1.38 & $(0.72-2.63)$ & $2.07^{* *}$ & $(1.26-3.40)$ & $2.39^{* * *}$ & $(1.66-3.44)$ & $2.35^{* * *}$ & $(1.64-3.35)$ \\
\hline Lowest & 1.13 & $(0.61-2.09)$ & 1.73 & $(0.98-3.10)$ & $2.68^{* * *}$ & $(1.86-3.87)$ & $2.71^{* * *}$ & $(1.90-3.87)$ \\
\hline
\end{tabular}

*** $p<0.001,{ }^{* *} p<0.01,{ }^{*} p<0.05$. Variables in models included sex, child age, birthweight, maternal education, mother's smoking history, place of residence, and wealth quintile. Low birth weight for children was defined as less than $2.5 \mathrm{~kg}$.

stunting risk factors associated with maternal and antenatal health.

Policies to curb stunting in Rwanda are already underway to help children in the poorest sectors of the population, including the National Multisectoral Strategy to Eliminate Malnutrition (2010), the National Community Based Nutritional Protocol 2010, the District Action Plans to Eliminate Malnutrition (2011), and the Joint Action Plan to Fight Malnutrition (2013) [37]. Further, Rwanda's free public education program for children younger than 18 years old and an extensive adult literacy program to address the limited education of current mothers, may also help to prevent the perpetuation of these disparities [38, 39]. Moreover, to increase food intake, there are school feeding programs, kitchen garden initiatives, the one-cow one-family program, and a distribution of livestock to the poorest families. It will be imperative to monitor the progress of these policies and initiatives to mitigate the burden of stunting among children in Rwanda. Further, there is evidence that enrollment in Rwanda's health insurance scheme (Mutuelles), which covers nutrition-related promotional and preventive services, could help combat stunting nationally [40].

In the long-term, a high level of stunting among children has implications for future economic security as they transition into adulthood, which can serve as a potential threat to Rwanda's ability to achieve its Vision 2020 development goals, broadly defined as "macroeconomic stability and 
wealth creation to reduce aid dependency", "structural economic transformation" and "creating a productive middle class and fostering entrepreneurship" [9]. Therefore, it is important to undertake additional research to help explain this discrepancy between national economic growth, health progress, and malnutrition. For example, although not directly examined in this paper, a study by Milman and colleagues suggested that countries devoting more resources to agriculture witness worse stunting levels than countries with a more diversified economy [41]. Since such a high proportion of Rwanda's economy is generated from agricultural production, with agriculture, forestry, and fishing comprising $31 \%$ of the 2017 gross domestic product, this suggests the need for additional analyses to explore this potential association in the Rwanda context [42].

\section{Limitations}

Though our study provides a comprehensive overview of the best population-based data available between 2000 and 2015, it has important limitations as a secondary analysis. The DHS data are cross-sectional; therefore, examining a temporal relationship between relevant risk factors and stunting is not possible. Further, since DHS data only includes families living in households, it omits potentially relevant, high risk groups such as homeless, refugee, hospitalized or otherwise institutionalized children, which may bias our results towards an underestimate of the burden of stunting. There are limitations in the wealth index as well; household income and wealth are not specifically measured by the DHS and the evaluation of wealth based on ownership of durable goods and household characteristics may not capture the complexity of resources available to individuals in a household. This metric serves purely as a proxy for socioeconomic status in our analysis. Additionally, adjusting scoring for households based on urban or rural residence was not introduced into the Rwanda DHS until 2015. Further, this analysis did not include all potentially relevant factors, such as psychosocial risk factors including maternal depression and intimate partner violence, as these were beyond the study's scope.

\section{Conclusions}

In spite of substantial country-wide economic gains over the past two decades, Rwanda has witnessed a relatively stagnant rate of childhood stunting since 2000, with only a marginal decrease in 2015. These findings can inform current programs underway and help to tailor future national strategies to make needed progress to reduce stunting among children in Rwanda. This will necessitate a multi-sectoral approach and one that reduces socioeconomic inequalities, dissolves rural and urban disparities, breaks barriers for women's access to education, increases access to safe water and sanitation services, as well as improves uptake of reproductive, maternal, and postnatal care. Progressive policies and programs that support these changes can also advance the national equity agenda by improving the wealth distribution and averting unnecessary suffering among children and their families. These policies and strategies will support Rwanda in achieving its Vision 2020 goals and promoting economic advancement in the long-term.

\section{Abbreviations}

DHS: Demographic and Health Survey; OR: Odds Ratio; SD: Standard Deviation; UNICEF: United Nations International Children's Emergency Fund; WHO: World Health Organisation

\section{Acknowledgements}

The authors would like to acknowledge the contributions of all survey staff for the Demographic Health Survey, whose diligent work to collect these data allow for important policy analysis.

\section{Authors' contributions}

$A B, A R, C K, F N$ and MF were involved with the conception and implementation of the project. $A B, A R, S P$, and $M F$ were involved with the design and analysis of the manuscript. $A B, M F, K D, M A, F N, C K$, and KWS were involved in the interpretation and writing of the manuscript. All authors contributed to reviewing the revisions and approving the final submitted manuscript.

\section{Funding}

None.

\section{Availability of data and materials}

All data come from the Rwanda Demographic Health Surveys completed between 2000 and 2015 - https://dhsprogram.com/what-we-do/survey/ survey-display-554.cfm. Additional information regarding the datasets used and analysed in this current study are available from the corresponding author on reasonable request.

Ethics approval and consent to participate

This is a secondary analysis of publicly-available, non-identifiable data and does not qualify as human subjects research.

\section{Consent for publication}

Not applicable.

\section{Competing interests}

The authors declare that they have no competing interests.

\section{Author details \\ ${ }^{1}$ University of Global Health Equity, Kigali Heights, Plot 772, KG 7 Ave., 5th Floor, PO Box 6955, Kigali, Rwanda. ${ }^{2}$ Harvard Medical School, Boston, MA, USA. ${ }^{3}$ Dartmouth Geisel School of Medicine, Hanover, NH, USA \\ ${ }^{4}$ Independent Consultant, Montréal, Québec, Canada. ${ }^{5}$ University of Virginia, Charlottesville, VA, USA. ${ }^{6}$ Partners In Health, Freetown, Sierra Leone. ${ }^{7}$ School of Public Health, Universite libre de Bruxelles, Brussels, Belgium.}

Received: 23 August 2019 Accepted: 6 January 2020

Published online: 20 January 2020

\section{References}

1. The State of Food Insecurity in the World 2005. Rome, Italy: Food and Agriculture Organization of the United Nations; 2005. http://www.fao.org/3/ a0200e/a0200e.pdf. Accessed 8 May 2019.

2. World Health Organization. 10 facts on nutrition. 2017. http://www.who.int/ features/factfiles/nutrition/en/. Accessed 8 May 2019.

3. Seress L. Morphological changes of the human hippocampal formation from midgestation to early childhood. In: Nelson CA, Luciana M, editors. editors Handbook of Developmental Cognitive Neuroscience. Cambridge: MIT Press; 2001. p. 45-58. 
4. Pomeroy, SL, Ullrich, NJ. Development of the nervous system. In: Polin Richard, Abman, Steven, Fox, William, editors. Fetal and Neonatal Physiology. 3rd. Philadelphia: Saunders; 2004. 2128.

5. Alderman H, Behrman JR, Hoddinott J. Economic and nutritional analyses offer substantial synergies for understanding human nutrition. J Nutr. 2007; 137:537-44.

6. Horton SML. Opportunities for Investments in Nutrition in Low-income Asia. Asian Dev Rev. 1999;2:246-73.

7. de Onis M, Frongillo EA, Blössner M. Is malnutrition declining? An analysis of changes in levels of child malnutrition since 1980. Bull World Health Organ. 2000;78:1222-33.

8. Annual Report on the Implementation of the Economic Development and Poverty Reduction Strategy (EDPRS) - 2008. Ministry of finance and economic planning, Republic of Rwanda; 2009. http://www.statistics.gov.rw/ file/274/download?token=IOGBZBTD.

9. Republic of Rwanda. Rwanda Vision 2020. 2012. http://www.minecofin.gov rw/fileadmin/templates/documents/NDPR/Vision_2020_.pdf. Accessed 10 Nov 2019

10. Farmer PE, Nutt CT, Wagner CM, Sekabaraga C, Nuthulaganti T, Weigel JL, et al. Reduced premature mortality in Rwanda: lessons from success. BMJ. 2013;346. https://doi.org/10.1136/bmi.f65.

11. ICF International. The DHS Program STATcompiler: Rwanda DHS Data, 2000-2015. STATCompiler - The DHS Program. 2019. https://www.statcompiler.com/en/.

12. Rusa L, Ngirabega Jde D, Janssen W, Bastelaere SV, Porignon D, Vandenbulcke W. Performance-based financing for better quality of services in Rwandan health centres: 3-year experience. Trop Med Int Health. 2009;14: 830-7.

13. Janssen W, Ngirabega Jde D, Matungwa M, Van Bastelaere S. Improving quality through performance-based financing in district hospitals in Rwanda between 2006 and 2010: a 5-year experience. Trop Doct. 2015;45:27-35.

14. Binagwaho A, Scott KW. Improving the World's health through the Post2015 development agenda: perspectives from Rwanda. Int J Health Policy Manag. 2015;4:203-5.

15. National Institute of Statistics of Rwanda (NISR) [Rwanda], Ministry of Health $(\mathrm{MOH})[$ Rwanda], and ICF International. Rwanda Demographic and Health Survey 2014-15. Kigali; Rockville: National Institute of Statistics of Rwanda, Ministry of Finance and Economic Planning; Ministry of Health; The DHS Program, ICF International; 2015. https://dhsprogram.com/pubs/pdf/FR316/ FR316.pdf

16. Institut National de la Statistique du Rwanda (INSR) and ORC Macro. Rwanda Demographic and Health Survey 2005. Kigali: INSR and ORC Macro; 2006. https://dhsprogram.com/pubs/pdf/FR183/FR183.pdf

17. Vinck P, Brunelli C, Takenoshita K, Chizelema D. Rwanda: comprehensive food security and vulnerability analysis and nutrition survey July 2009: National Institute of Statistics of Rwanda, Ministry of Finance and Economic Planning; United Nations World Food Programme; UNICEF; World Vision; 2009. http:// statistics.gov.nw/datasource/43. Accessed 23 May 2019.

18. Office National de la Population (ONAPO) [Rwanda] et ORC Macro. Enquête Démographique et de Santé, Rwanda 2000. Kigali: Ministère de la Santé, Office National de la Population et ORC Macro; 2001. https://dhsprogram. com/pubs/pdf/FR125/FR125.pdf

19. National Institute of Statistics of Rwanda (NISR) [Rwanda], Ministry of Health ( $\mathrm{MOH}$ ) [Rwanda], and ICF International. Rwanda Demographic and Health Survey 2010. Kigali: National Institute of Statistics of Rwanda, Ministry of Finance and Economic Planning; Ministry of Health; The DHS Program, ICF International; 2012. https://dhsprogram.com/pubs/pdf/FR259/FR259.pdf

20. de Onis M, Onyango A, Borghi E, Siyam A, Pinol A. WHO child growth standards: length/height-for-age, weight-for-age, weight-for-length, weightforheight and body mass index for-age: methods and development. Geneva; World Health Organization. https://www.who.int/childgrowth/ standards/Technical_report.pdf. Accessed 23 May 2019.

21. Stunting in a nutshell - Nutrition. World Health Organization. 2019. http:// www.who.int/nutrition/healthygrowthproj_stunted_videos/en/. Accessed 23 May 2019.

22. ICF International. MEASURE DHS biomarker field manual. Manual. Calverton: ICF International; 2012. https://www.dhsprogram.com/pubs/pdf/DHSM7/ DHS6_Biomarker_Manual_9Jan2012.pdf

23. Rutstein SO, Johnson K. The DHS wealth index. Calverton: ORC Macro: 2004 https://dhsprogram.com/pubs/pdf/cr6/cr6.pdf
24. El Kishawi RR, Soo KL, Abed YA, Muda WAMW. Prevalence and associated factors influencing stunting in children aged 2-5 years in the Gaza stripPalestine: a cross-sectional study. BMC Pediatr. 2017;17:210.

25. Walker SP, Chang SM, Wright A, Osmond C, Grantham-McGregor SM. Early childhood stunting is associated with lower developmental levels in the subsequent generation of children. J Nutr. 2015;145:823-8.

26. StataCorp. Stata Statistical Software: Release 12. College Station: StataCorp LP; 2011.

27. R Core Team. R: A language and environment for statistical computing. Vienna: R Foundation for Statistical Computing; 2013. http://www.R-project. org/

28. Nshimyiryo A, Hedt-Gauthier B, Mutaganzwa C, Kirk CM, Beck K, Ndayisaba A, et al. Risk factors for stunting among children under five years: a crosssectional population-based study in Rwanda using the 2015 demographic and health survey. BMC Public Health. 2019;19:175.

29. Uwiringiyimana V, Ocké MC, Amer S, Veldkamp A. Predictors of stunting with particular focus on complementary feeding practices: a cross-sectional study in the northern province of Rwanda. Nutrition. 2019;60:11-8.

30. Kirk CM, Uwamungu JC, Wilson K, Hedt-Gauthier BL, Tapela N, Niyigena P, et al. Health, nutrition, and development of children born preterm and low birth weight in rural Rwanda: a cross-sectional study. BMC Pediatr. 2017;17: $1-9$.

31. Zere $E$, Mclntyre D. Inequities in under-five child malnutrition in South Africa. Int J Equity Health. 2003;2:7.

32. Ramli, Agho KE, Inder KJ, Bowe SJ, Jacobs J, Dibley MJ. Prevalence and risk factors for stunting and severe stunting among under-fives in North Maluku province of Indonesia. BMC Pediatr. 2009;9:64.

33. Kikafunda JK, Walker AF, Collett D, Tumwine JK. Risk factors for early childhood malnutrition in Uganda. Pediatrics. 1998;102:e45.

34. Fernald $L$, Neufeld $L$. Overweight with concurrent stunting in very young children from rural Mexico: prevalence and associated factors. Eur J Clin Nutr. 2007;61:623-32.

35. Stevens GA, Finucane MM, Paciorek CJ, Flaxman SR, White RA, Donner AJ, et al. Trends in mild, moderate, and severe stunting and underweight, and progress towards MDG 1 in 141 developing countries: a systematic analysis of population representative data. Lancet. 2012;380:824-34.

36. National Institute of Statistics Rwanda. ElCV5 Presentation. http://www. statistics.gov.rw/publication/eicv5-power-point-presentation. Accessed 10 Nov 2019.

37. Policies in Rwanda - Global database on the Implementation of Nutrition Action (GINA). World Health Organization. 2012. https://extranet.who.int/ nutrition/gina/en/policies/1535. Accessed 23 May 2019.

38. Nine Years Basic Education Implementation: Fast Track Strategies. Kigali: Ministry of Education, Republic of Rwanda; 2008. https://planipolis.iiep. unesco.org/sites/planipolis/files/ressources/rwanda_9_years_basic_ education.pdf. Accessed 23 May 2019.

39. Paxton W. IPAR observatory report: the Rwandan education and skills system. Kigali: Institute of Policy Analysis and Research-Rwanda; 2012. https://opendocs.ids.ac.uk/opendocs/bitstream/handle/123456789/9660/ Education\%200bservatory\%20Report.pdf;sequence=1

40. Lu C, Mejia-Guevara I, Hill K, Farmer P, Subramanian SV, Binagwaho A. Community-based health financing and child stunting in rural Rwanda. Am J Public Health. 2015:106:49-55.

41. Milman A, Frongillo EA, de Onis M, Hwang J-Y. Differential improvement among countries in child stunting is associated with long-term development and specific interventions. J Nutr. 2005;135:1415-22.

42. GDP National Accounts, 2017. National Institute of statistics of Rwanda, Ministry of Finance and economic planning, Republic of Rwanda; 2018.

\section{Publisher's Note}

Springer Nature remains neutral with regard to jurisdictional claims in published maps and institutional affiliations. 